\title{
Avoidance Response: A More Important Determinant of Population Immediate Decline in Guppy Fish (Poecilia Reticulata Peters, 1859) Exposed to Pesticides.
}

\section{Olusola Ojo Ogunfeitimi ( $\square$ ogunfeitimisola@gmail.com )}

Ecotoxicology and Conservation Unit, Ecotoxicology Laboratory, Department of Zoology, University of Lagos, Akoka Yaba, Lagos, Nigeria. https://orcid.org/0000-0002-5087-1272

\section{N. H. Amaeze}

Ecotoxicology and Conservation Unit, Ecotoxicology Laboratory, Department of Zoology, University of Lagos, Akoka Yaba, Lagos. Nigeria.

\section{H. C Umeokeke}

Ecotoxicology and Conservation Unit, Ecotoxicology Laboratory, Department of Zoology, University of Lagos, Akoka Yaba, Lagos, Nigeria.

\section{E. T. Soriwei}

Ecotoxicology and Conservation Unit, Ecotoxicology Laboratory, Department of Zoology, University of Lagos, Akoka Yaba, Lagos, Nigeria.

\section{A. S. Labinjo}

Ecotoxicology and Conservation Unit, Ecotoxicology Laboratory, Department of Zoology, University of Lagos, Akoka Yaba, Lagos, Nigeria.

\section{Research Article}

Keywords: Population Immediate Decline (PID), Paraquat, Dichlorvos, Non-Forced System, Forced System, Multi-compartmented static system, Environmental risk assessment.

Posted Date: April 30th, 2021

DOl: https://doi.org/10.21203/rs.3.rs-451385/v1

License: (a) (i) This work is licensed under a Creative Commons Attribution 4.0 International License. Read Full License

Version of Record: A version of this preprint was published at Asian Journal of Environment \&amp; Ecology on June 22nd, 2022. See the published version at 
https://doi.org/10.9734/ajee/2022/v18i230312. 


\section{Abstract}

This study, investigated the ability of Paraquat (herbicide) and Dichlorvos (insecticide) to elicit avoidance response in population of Guppy fish, Poecilia reticulata and predict the population immediate decline (PID) of $P$. reticulata when exposed to both agro-chemicals. A 96-h forced system (FS) bioassay was each conducted in five duplicate systems, each with a control experiment. The avoidance response was examined using non-forced multi-compartmented static system (NFS). The guppies ( $n=3$ guppies per concentration of 6 compartments in quadruplet) were exposed to a gradient of Paraquat $(0,2.5,5.0,7.5$, 10.0 and $15.0 \mathrm{mg} / \mathrm{L})$ and Dichlorvos $(0,1.6,2.6,3.0,3.2$ and $4.0 \mathrm{mg} / \mathrm{L})$. Their distributions were examined at 20 min intervals for a 3-h period ( $n=9$ observation periods). The results from $96-\mathrm{h}$ FS were doesdependent with highest percentage mortality being $85.7 \%$ for Paraquat and $78.6 \%$ for Dichlorvos in respective highest concentrations. The 3-h NFS exposure showed statistically significant concentrationdependent spatial avoidance. The $P$. reticulata avoided the lowest concentration of Paraquat $(2.5 \mathrm{mg} / \mathrm{L})$ and Dichlorvos $(1.6 \mathrm{mg} / \mathrm{L})$ by $68.3 \%$ and $48.3 \%$ respectively. The avoidance increased significantly $(\mathrm{p}<$ 0.005 ) to $75 \%$, for the highest concentrations of both test chemicals (15.0 and $4.0 \mathrm{mg} / \mathrm{L}$ ). The $3-\mathrm{hr} \mathrm{AC} \mathrm{C}_{50}$ value revealed that the guppies were more sensitive to Paraquat $(0.37 \mathrm{mg} / \mathrm{L})$ than Dichlorvos $(1.73$ $\mathrm{mg} / \mathrm{L}$ ). The PID was driven by the avoidance behaviour (NFS) of the guppies rather than mortality (FS). The FS heretofore overestimate environmental risk assessment of contamination due to mandatory exposure of mobile organisms to contaminants. Rather than the traditional FS systems, NFS should be adopted and incorporated in typical bioassays for better predictive results.

\subsection{Introduction}

There has been a worldwide concern on the ecological impacts of economic poisons (synthetic pesticides) on living organism, especially non-target species. Farming is the biggest consumer of pesticides, where they are employed for pests control to enhance crop yield. Pesticides are also useful in mitigating the spread of bugs, microbes, parasites, and as biocidal agents for protecting various items of value (Gilden et al., 2010). Given the broad spectrum nature of most pesticides, inadvertent exposures often result in harm to biota and humans Sarwar (2015). Exposure to low concentrations of pesticides have been attributed to detrimental effects on various life stage of organisms (Damalas and Eleftherohorinos, 2011, Omoniyi et al., 2013). Pesticides at a high concentration are known to diminish the endurance, development and multiplication of fish, and produce numerous obvious consequences for fish (Rahman et al., 2002). The danger of a synthetic chemical is subject to the actual concentration of the substance entering an organism or its concentration at the target receptor in living organisms (Ayoola, 2008). In order to avert the most harmful effects of pesticides, there is need to understand speciesspecific responses of various organism us and build relevant quantitative data to guide extension services. To this end this study investigated the acute toxicity and avoidance responses of an important mosquito bio-control fish, the guppy fish, Poecilia reticulata to pesticide, Paraquat and Dichlovors.

Paraquat (1, 1'- Dimethyl-4, 4'- bipyridinium dichloride) is a common brand of herbicides for the control of a few expansive leaves and grasses in ranches and different weeds in non-crop land/urban and 
residential settings. In the last six decades, it has been sold under various brand names, for example, Gramoxone, Crisquat, Dextrone X and Esgram in roughly 100 countries (Arivu et al., 2015). Banaee et al. (2013) noted that Paraquat is a contact and non-specific herbicide that can be utilized to control a few terrestrial and aquatic weeds. Besides pests and other animals, Paraquat is lethal to humans and enters the human system through inward breath, ingestion and damaged skin tissues (Arivu et al., 2015). Notwithstanding the danger of this herbicide, the active ingredient is quickly absorbed by clay and silt particles in the dirt and doesn't leave any viable soil buildup (Fryer, 1977), hence its adoption.

A commonly used synthetic insecticide is dichlorvos, otherwise called DDVP (2, 3-dichlorovinyl dimethyl phosphate). It is an organophosphate insecticide cum pesticide (USEPA, 2007). It is commercialized under different names, for example, DDVP, Dedevap, Nogos, Nuvan, Phosvit, Vapona, Sniper and Daksh in developed and developing countries (Owoeye et al., 2012). It is the most commonly used organophosphate pesticide in developing nations (Binukumar and Gill, 2010) for both domestic and agricultural purposes. It is additionally utilized as an antihelminthic operator on canines, ponies and swine (USEPA, 1994). It has also been utilized in fish cultivation to destroy shellfish ectoparasites (Varó, et al., 2003). Dichlorvos doesn't firmly ingest bright radiation over $240 \mathrm{~nm}$ (Howard, 1991) and subsequently it is probably not going to experience photodegradation in the atmosphere. In solution, dichlorvos is subject to both abiotic and biotic degradation, with the prevalent system being hydrolysis reaction which turns into the significant instrument for debasement (Faust and Suffet, 1966; Lamoreaux and Newland, 1978). Dichorvos is hydrolyzed to dichloroethanol, dichloroacetaldehyde, dichloroacetic corrosive, dimethylphosphate and dimethylphosphoric corrosive acid (WHO, 1989). This degradation is increasingly quick in basic media (Lamoreaux and Newland, 1978) and intense temperature (Faust and Suffet, 1966). In very damp soils, hydrolysis reaction like those in aquatic environment is required to happen (Okoroiwu and Iwara, 2018).

A major challenge in assessing responses of organisms to toxicants such as pesticides is the bioassay design. In many toxicity testing bioassays where the usual reactions, such as tolerance, growth, prevalence, and common endpoints are investigated, forced exposure system are typically used. These involves the introduction of organisms into a confined space for the purpose of exposure to predetermined concentrations of toxicants. Despite the fact that this method can help in predicting the impact of continuous exposure to pollutant, it cannot predict the ways in which organisms respond under normal circumstances where an organism has the capacity to move away from contaminated areas (Moreira-Santos et al., 2008).

In nature, animals such as fishes often have the freedom to move away from unfavorable conditions. Thus, in a non-forced environment, avoidance can be used as a plausible response to assess the potential population decline of aquatic organism, driven by complex stress, and subsequent consequences for community structure and environmental dynamics (Rosa et al., 2012; Araújo et al., 2016a, 2017). Avoidance responses should be considered as an integral tool for traditional assessments, which improves the biological importance in assessing the natural hazards of pollution (Moreira-Santos et al., 2008; Rosa et al., 2012). In the present study, a non-forced contamination gradient has been 
adopted to help in understand the spatial distribution and rapid population decline of guppy fishes upon exposure to Paraquat and Dichlorvos. Hence, the objectives of this survey were: (i) To determine the capacity of Paraquat and Dichlorvos to cause an avoidance response in $P$. reticulata, (ii) To predict the Population Immediate Decline (PID) at the local scale, caused by exposure to both pesticides, by integrating both lethality and avoidance responses in a very short-term exposure. (iii) Determine whether mortality can be overestimated when using forced and continuous exposure to assess hazardous effects.

\subsection{Materials And Methods}

\subsection{Test animal: acquisition and acclimation}

Guppy fishes, Poecilia reticulata (Chordata, Poeciliidae, Animalia, Actinopterygii) were collected using scoop net from storm channels at the Faculty of Science, University of Lagos and transported to the laboratory in a tank filled with water from the point of collection. The use of the fish was approved by the Ethics Committee on the Use of Animals (Lagos University Teaching Hospital). The organisms were acclimated under laboratory conditions at the Ecotoxicology Laboratory of the Department of Zoology, University of Lagos for at least one week prior to the tests, following OECD guidelines (OECD, 2000). Only F1 generations were employed in the actual bioassay. Fishes were kept in $50 \mathrm{~L}$ aquaria filled with dechlorinated municipal water. The cultures were constantly aerated and the water was renewed by $30 \%$ every week. The animals were fed daily, with commercial Coppens ${ }^{\circledR}$ fish food until $24 \mathrm{~h}$ prior the experiments. The conditions in the culture media were maintained as follows: $\mathrm{pH}(6.4-7.2)$, conductivity (0.15-0.30 mS $\left.\mathrm{cm}^{-1}\right)$, total dissolved solid (113-125 $\left.\mathrm{mg} \cdot \mathrm{L}^{-1}\right)$, photo period (12:12-h. light: dark) and temperature $\left(25.8\right.$ to $\left.26.3^{\circ} \mathrm{C}\right)$.

\subsection{Test chemicals}

The Pesticides for this study were the herbicide; Paraforce, (manufacturer: Nanjing Redsum Biochemistry Co Ltd., Nanjing City, China), active ingredient $276 \mathrm{~g}$ of Paraquat dichloride (200g Paraquat/L) and Sniper (manufacturer: Forward (Beihai) Hepu Pesticide Co. Ltd. Guangxi, China), active ingredient $1000 \mathrm{~g} / \mathrm{L}$ of 2, 3-dichlorovinyldimethyl phosphate (DDVP). Both pesticides were procured from Lagos State Agricultural Input Supply Office, Oko Oba Agege, Lagos State. Prior each toxicity and avoidance test, stock solutions of Paraquat dichloride and Dichlorvos were prepared at concentrations of $1000 \mathrm{mg} / \mathrm{L}$ each dispensing an aliquot to be measured out in distilled water. Subsequent dilutions were made with culture water in the experimental tanks. Both pesticides were stored at room temperatures $\left(<33^{\circ} \mathrm{C}\right)$ prior to the bioassay.

\subsection{Acute toxicity tests using Forced exposure Systems (FS)}

Acute toxicity tests were performed with the fish for the two pesticides in order to determine the $\mathrm{LC}_{50}$ values for each pesticide before the avoidance tests. The Dichlorvos and Paraquat concentrations used in the tests $\left(0,1.60,2.60,3.00,3.20\right.$ and $4.00 \mathrm{mgL}^{-1}$ and $0,2.50,5.00,7.50,10.00$ and $\left.15.00 \mathrm{mgL}^{-1}\right)$ 
respectively. The tests were carried out in duplicate using 7 fishes per $3 \mathrm{~L}$ glass aquarium per concentration, at a temperature of $26.20 \pm 0.4{ }^{\circ} \mathrm{C}$ and a photoperiod of 12:12 $\mathrm{h}$ (light: dark).

\subsection{Design of the Non-Forced multi- compartment exposure System (NFS)}

Non-forced avoidance tests were performed in a free-decision, static multi-compartment system, based on the method of Araújo et al. (2014a). The system was made out of interconnected compartments developed from purpose built PET bottles without any tainting material. The chambers were linked with non-lethal transparent plastic paste (Zuma PVC glue). The system had an all-out length of $186 \mathrm{~cm}$ and a total volume of $9000 \mathrm{ml}$, and each compartment had a volume of $1500 \mathrm{ml}$. For the experiment, the compartments were loaded up with $1 \mathrm{~L}$ of culture medium containing each of the test pesticides at various concentration.

\subsection{Calibration of the Non-Forced multi- compartment System (NFS)}

The linear gradient of the contaminant was first validated without fishes in the NFS experiments. For this, various concentrations $\left(0,0.2,0.4,0.6,0.8\right.$, and $\left.1.0 \mathrm{mgL}^{-1}\right)$ of analytical grade sodium chloride $(\mathrm{NaCl})$ in distilled water were prepared. $\mathrm{NaCl}$ concentrations were measured indirectly by conductivity at $0 \mathrm{hr}$ (initial) and after $3 \mathrm{hr}$ (final). The initial concentrations (at $0 \mathrm{~h}$ ) within each compartment were (mean and standard deviation): $0.07 \pm 0,0.14 \pm 0,0.29 \pm 0.004,0.51 \pm 0.004,0.71 \pm 0.004$, and $1.125 \pm 0.005 \mathrm{mgL}^{-1}$ ). Before dispensing the $\mathrm{NaCl}$ salt in the system, the compartments were isolated from each other using plasticine plugs. After introduction of the different amounts of $\mathrm{NaCl}$ in the compartments, the plugs were removed, resulting in a linear gradient. The calibration was carried out in quadruplets, in the dark. Subsequently, a control distribution experiment was performed to confirm that the fish did not exhibit a preference for any particular compartment. To this end, three organisms were introduced into to each compartment containing only culture water (no gradient) and the number of fishes in each compartment was recorded after 3-h.

\subsection{Avoidance tests with Paraquat and Dichlorvos}

The avoidance tests were performed separately in an arrangement of NFS, mimicking a spatially more extensive and more permanent slope in accordance with the $96-\mathrm{h} \mathrm{LC}_{50}$ values of $\mathrm{FS}$ of the guppies, singly to both pesticides. The concentrations were as follows (in $\mathrm{mgL}^{-1}$ ): 0 (control), 2.50, 5.00, 7.50, 10.00 and 15.00 and 0 (control), 1.60, 2.60, 3.00, 3.20 and 4.00 for Paraquat and Dichlorvos respectively. In each test, three fish were introduced per concentration, totaling 18 individuals in each system. The procedures used to dispense the test chemicals and fishes in the system were those described in the previous calibration procedure. The tests were completed in quadruplets, in the dark to minimize external interferences.

\subsection{Statistical analysis}


The proportion of organisms recorded in each compartment at various experimental times were arcsine transformed. The arbitrary dispersion of organisms in control medium and avoidance tests with both pesticides were evaluated with a mixed-design (time as a repetitive measure, within factor, and compartment as between factor), analysis of variance (ANOVA). Mauchly's test was utilized for sphericity test. Where sphericity was infringed (the variances of the differences are not equal: $p<0.05$ ), GreenhouseGeisser correction was applied (Ehiguese, et al., 2019. See Tables S1a, S1b, S1c, S2a, S2b, S2c, S3a, S3b and S3c- Supplementary Material)

The outcomes (number of dead organisms) of the acute tests were analyzed using Probit analysis (Finney, 1971) to compute the $96-\mathrm{h} \mathrm{LC}_{50}$ values for the individual test chemical and the corresponding $95 \%$ confidence interval $(\mathrm{Cl})$. Unidirectional ANOVA was used followed by the LSD multiple comparisons post hoc test $(p<0.05)$ to analyze the results of the calibration tests and avoidance tests. For the calculation of avoidance (\%), the number of avoiders for each concentration was determined as the difference between the number of expected organisms $\left(\mathrm{N}_{\mathrm{E}}\right)$ and the number of organisms observed $\left(\mathrm{N}_{\mathrm{O}}\right)$ : Avoiders $=N_{E}-N_{O}$. The $N_{E}$ was determined as described by Moreira-Santos et al. (2008): for the compartment with the highest concentration of the test chemical, the $N_{E}$ was equal to the number of fish introduced into the compartment at the beginning of the test; for the remaining compartments, $N_{E}$ included the organisms initially introduced into the compartment, plus the organisms introduced into the adjacent compartment with greater concentration. Initially, since each compartment contained three fishes, the value of $\mathrm{N}_{E}$ was 3 for the most contaminated compartment (considered the first compartment). The $\mathrm{N}_{\mathrm{E}}$ value for the adjacent compartment (second compartment) was 6 (3 organisms inserted in this compartment plus 3 organisms that are expected to move from the first compartment), while for the last compartment (sixth, not contaminated) it was 18 . With respect to the number of organisms observed for each concentration, the organisms found in that compartment and those found in higher concentrations were considered as $\mathrm{N}_{0}$. Finally, for the control compartment, because this compartment contained the water in which the organisms were grown, it was not expected to be avoided; therefore, it was 18. The avoidance percentage for each compartment was calculated as follows: (Avoiders $/ \mathrm{N}_{\mathrm{E}}$ ) *100. The avoidance percentages for each concentration were used to obtain $\mathrm{AC}_{50}$ values (concentration that avoids $50 \%$ of the exposed organisms) and the corresponding $95 \%$ confidence interval using Probit analysis. The avoidance and mortality percentages were subsequently integrated to calculate the $\mathrm{PID}_{\mathrm{x}}$ ( $\mathrm{x}$ in percentage) induced by each chemical test concentration that simultaneously caused a ' $y$ ' mortality percentage (i.e., the $96-\mathrm{h} \mathrm{LC}_{\mathrm{y}}$ ) and an avoidance percentage ' $\mathrm{w}$ ' (that is, the 3-hour $\left.\mathrm{AC}_{\mathrm{w}}\right)$, as described by Rosa et al., (2012): $=(100 \mathrm{y}+100 \mathrm{w}-\mathrm{yw}) / 100$

The calculation of the immediate population decline was based on the fact that some of the fish first flee (\% avoidance), and that mortality is then determined based on the remaining organisms (those that did not show evasion). The $\mathrm{PID}_{50}$ values (the concentration that causes an immediate population decrease of $50 \%$ of the exposed organisms) and the corresponding confidence interval were also obtained using Probit analysis. All statistical analysis was performed using SPSS Version 20 (IBM). 


\subsection{Results}

\subsection{Acute toxicity test of Paraquat and Dichlorvos to Poecilia reticulata.}

The percentages responses in the 96-h FS acute toxicity test recorded at various concentrations of Paraquat and Dichlorvos are presented in Tables S2 and S3 - Supplementary Material respectively.

In particular, for the FS exposure to Paraquat mortality per concentrations after 96 -h were $0 \%$ (control), $0 \%$ (2.5 mg/L), 21.43\% (5.0 mg/L), 35.71\% (7.5 mg/L), 71.43\% (10.0 mg/L), 85.71\% (15.0 mg/L) while for Dichlorvos exposure, it was 0\% (control), 21.43\% (1.6 mg/L), 42.86\% (2.6 mg/L), $50 \%$ (3.0 mg/L), 50.0\% (3.2 mg/L), 78.57\% (4.0 mg/L). Unconsciousness and loss of steadiness were displayed by test organisms in the first 24-h at highest concentrations of both chemicals. The measure of relative potency of toxicants (i.e. toxicity factor) ascribed Dichlorvos to be more lethal to the guppies than Paraquat by a factor of 2.9 (Table 1). Similar trends were followed at $24 \mathrm{hr}, 48 \mathrm{hr}$ and $72 \mathrm{hr}$ of forced exposure (Tables S4a, S4b and S4c - Supplementary Material).

Table 1

Comparative assessment of relative 96-h acute toxicity of Herbicide (Paraquat) and Insecticide (Dichlorvos) $\mathrm{mg} / \mathrm{L}$ acting singly against Poecilia reticulate in Forced System (FS)

\begin{tabular}{|c|c|c|c|c|c|}
\hline Chemical & $\begin{array}{l}\mathrm{LC}_{50} \\
\text { (Interval) }\end{array}$ & Slope \pm SE & Probit line equation & DF & TF \\
\hline Paraquat (mg/L) & $8.20(6.69-10.09)$ & $4.46 \pm 1.0$ & $Y=-3.75+4.13 x$ & 3 & 2.9 \\
\hline Dichlorvos (mg/L) & $2.84(\mathrm{~N} / \mathrm{A})$ & $3.66 \pm 1.26$ & $Y=-1.63+3.63 x$ & 3 & 1 \\
\hline
\end{tabular}

\subsection{Avoidance system calibration and control tests}

The results of the calibration of the avoidance system using $\mathrm{NaCl}$ revealed that in the absence of the guppy fishes, the gradient was maintained after $3-h\left(p<0.05 ; F_{5,18}=755.024\right)$, since statistically significant differences $(p<0.05)$ existed among the concentrations in the compartments. This affirmed the soundness and appropriateness of the set up for avoidance experiment. However, the fitness of the $\mathrm{NaCl}$ gradient curve was checked by linear regression analysis of the initial and final concentrations after 3-h $\left(Y=0.115+7764 ; r^{2}=0.974\right.$ and $\left.r=0.987\right)$. After $3-h$, the mean and standard deviation values for the $\mathrm{NaCl}$ concentrations in the validation test without fish were $0.08 \pm 0.007,0.18 \pm 0.008,0.34 \pm 0.0008,0.52$ $\pm 0.001,0.7 \pm 0.02$, and $1.02 \pm 0.048 \mathrm{mg} / \mathrm{L}$ (Table S1 - Supplementary Material). In the control fish distribution experiment without Paraquat and Dichlorvos, an arbitrary conveyance with no statistical significant differences in the percentages (with no inclination for any compartment) of the organisms throughout the system were observed after $3-h\left(p>0.05 ; F_{5,18}=2.16\right)$. The mean distribution and 
standard deviation at the end of the control avoidance test of $P$. reticulata ( \pm standard deviation) per compartment were as follows: $3.25 \pm 0.5,2.50 \pm 0.58,3.25 \pm 0.5,2.50 \pm 0.58,3.25 \pm 0.5$, and $3.0 \pm 0.59$ respectively. The relative percentages and standard deviations of organisms observed in each compartment at the end of the 3-h observation is presented in Fig. 2.

\subsection{Avoidance response of the guppy fish, Poecilia reticulata to the exposed pesticides}

In the NFS tests with each pesticide the distribution of $P$. reticulata was concentration-dependent indicating avoidance behaviour. In the highest concentrations of $15.0 \mathrm{mgL}^{-1}$ and $4.0 \mathrm{mgL}^{-1}$ of Paraquat and Dichlorvos exposures respectively, 54 organisms (75\%) was found to avoid both considering the four replicates (a total of 72 organisms), while zero organisms ( $0 \%$ ) avoided the control compartments ( 0 $\mathrm{mgL}^{-1}$ ) as the fishes tend to migrate towards uncontaminated compartments (Tables S4 and S5 Supplementary Material).

The statistical analysis (Unidirectional ANOVA and LSD multiple comparison post hoc test) of $P$. reticulata distribution in the gradient of Paraquat $\left(F_{5,18}=206.80 p<0.05\right)$ and Dichlorvos $\left(F_{5,18}=126.96\right.$ $p<0.05$ ) indicated that the organisms significantly preferred the less contaminated compartments for survival during the 3 -h exposure period. In the presence of the contaminants, changes in the pattern of interaction such as competition and aggressiveness among the test organisms occurred i.e. preferential behaviour was displayed by the organisms to lesser contaminated compartments. By and large, $P$. reticulata migrated from more polluted compartments to uncontaminated compartments thus maintaining a strategic distance from aggressive concentration of test chemicals.

The mean distributions of fishes were determined by concentration gradient with individuals tending to migrate to less contaminated compartments. At 1-h of exposure to both pesticides, the guppy fish distribution in the contaminant gradients indicated that they preferred significantly (Paraquat $\mathrm{F}_{5,18}=$ $98.509 p<0.05$; Dichlorvos $F_{5,18}=38.12 p<0.05$ ) the uncontaminated compartments. A similar statistically significant response pattern was observed after 2-h (Paraquat $F_{5,18}=94.25 p<0.05$; Dichlorvos $\left.F_{5,18}=29.25 p<0.05\right)$ and 3 -h of exposure (Paraquat $F_{5,18}=206.8 p<0.05$; Dichlorvos $F_{5,18}=$ $126.96 \mathrm{p}<0.05)$ (Figs. 3).

\subsection{Population Immediate Decline (PID)}

Regarding avoidance and mortality, Population Immediate Decline (PID) was predicted from the number of organisms that moved away toward other compartments and non-avoiders that might die. If mortality alone is considered, the hazard is underestimated, because part of the population which are mobile (i.e. avoiders) are not considered in the estimation of population decrease. In all the scenarios, Population Immediate Decline (PID) curves from Non-Forced System (NFS) followed the same trend with the avoidance curves of $P$. reticulata for both test chemicals, as no mortality was recorded in the non-forced system (NFS). The population decline curves for various possible scenarios are represented in Fig. 4. 


\section{$\mathrm{AC}_{50}, \mathrm{LC}_{50}$, and $\mathrm{PID}_{50}$}

The calculated median concentrations of the pesticides causing avoidance $\left(\mathrm{AC}_{50}\right)$, mortality $\left(\mathrm{LC}_{50}\right)$ and population immediate decline $\left(\mathrm{PID}_{50}\right)$ of exposed guppies exposed to both pesticides considering mortality in the FS and NFS are presented in Table 2. The $\mathrm{AC}_{50}$ obtained specifically for Paraquat (0.37 $\mathrm{mg} / \mathrm{L}$ ) at $96-\mathrm{h}$ of mortality and $3 \mathrm{hr}$ of avoidance was about 4.7 times more sensitive than Dichlorvos $(1.73 \mathrm{mg} / \mathrm{L})$. The comparison of $A_{50}$ and $L_{50}$ values showed that the avoidance response was approximately 2 (Dichlorvos) to 22 (Paraquat) times more sensitive response than mortality ( $\mathrm{LC}_{50}$ value). Similar trends were observed at 24-h, 48-h, and $72 \mathrm{~h}$ of mortality and $3 \mathrm{hr}$ of avoidance response. In each case, Paraquat (116, 41 and 28 times) was profoundly more sensitive than Dichlorvos (12, 3 and 2 times) with respect to Avoidance-concentration to Mortality-concentration (Tables S5a, S5b and S5c Supplementary Material). The $\mathrm{PID}_{50}$ and $\mathrm{AC}_{50}$ values were similar in non-forced exposure, since there was no mortality in the non-forced exposure system.

Table 2

Values (in $\mathrm{mg} / \mathrm{L}$ ) of $\mathrm{AC}_{50}, \mathrm{LC}_{50}$, and $\mathrm{PID}_{50}$ (median concentrations that cause avoidance, mortality, and population immediate decline, respectively) in Guppy fish, Poecilia reticulata exposed to Paraquat and Dichlorvos in Forced System (FS) and Non-Forced multi-compartment exposure Systems (NFS)

\begin{tabular}{|llllll|}
\hline Chemicals & $\begin{array}{l}\mathrm{AC}_{50} \\
(\mathrm{NFS})\end{array}$ & $\begin{array}{l}\mathrm{LC}_{50} \\
(\mathrm{NFS})\end{array}$ & $\begin{array}{l}\mathrm{PID}_{50} \\
(\mathrm{NFS})\end{array}$ & $\mathrm{LC}_{50}(\mathrm{FS})$ & PID $_{50}(\mathrm{FS})$ \\
\hline Paraquat mg/L (CL) & $\begin{array}{l}0.37 \\
(\mathrm{~N} / \mathrm{A})\end{array}$ & $>15$ & $0.37(\mathrm{~N} / \mathrm{A})$ & $\begin{array}{l}8.20(6.69- \\
10.09)\end{array}$ & $\begin{array}{l}1.34(0.34- \\
2.14)\end{array}$ \\
\hline $\begin{array}{l}\text { Dichlorvos mg/L } \\
\text { (CL) }\end{array}$ & $\begin{array}{l}1.73 \\
(\mathrm{~N} / \mathrm{A})\end{array}$ & $>4$ & $1.73(\mathrm{~N} / \mathrm{A})$ & $2.85(\mathrm{~N} / \mathrm{A})$ & $1.31(0.56-$ \\
\hline
\end{tabular}

KEY: CL: Confidence Limit, NA: Not Available. NFS: Non-forced System FS: Forced System.

\subsection{Discussion}

The findings from this study has elucidated the responses of the important mosquito bio-control fish, $P$. reticulata to two selected agrochemicals typically used for insect pest and weed control in urban farms. The $96-\mathrm{h} \mathrm{LC}_{50}$ values for Paraquat and Dichlorvos $(8.20$ and $2.84 \mathrm{mg} / \mathrm{L}$ respectively) obtained from this study demonstrated that both pesticides were acutely toxic to $P$. reticulata thus, threatening their survival especially in chronic exposure situations due to runoffs from farmlands. This threat is heightened by the fact that the toxicity of both pesticides increased with duration within the $96-\mathrm{h}$ period. The $96 \mathrm{hr}-\mathrm{LC}_{50}$, value of Dichlorvos exposure in the present study was slightly higher than $1.84 \mathrm{mg} / \mathrm{L}$ reported by Günde and Yerli, (2012) for the same species. Several authors have also reported similar acute toxicity responses to Dichlorvos even with other fish species, pointing to a rather consistent pattern of response to this insecticide exposure. For example, some reported $\mathrm{LC}_{50}$ values following exposures to Dichlorvos include; Anabas testudineus - 2.35mg/L (Patar et al., 2015); Aphanius iberus - 3.17mg/L (Varó et al., 2008); 2.3mg/L (Verma et al., 1982) and Dicentrarchus labrax-3.5mg/L (Varơ et al., 2008). Overall, the 
WHO (1989) noted that for freshwater and estuarine fishes, Dichlorvos is ranked as moderate to highly toxic and $96-\mathrm{h} L C_{50}$ values have been found to range from 0.2 to $12 \mathrm{mg} / \mathrm{L}$, within which the values for the current study lies.

The $96-\mathrm{h} \mathrm{LC}_{50}$ of Paraquat on the exposed guppies in this study $(8.20 \mathrm{mg} / \mathrm{L})$ was also comparable to values from previous studies such as that of Kamwing and Furtado (1977) who reported 96-h LC Lo $_{0}$ of 7ppm for Raspora trilineats. Oloruntuyi et al. (1992) however reported 90 ppm 96-h LC Lo $_{0}$ value for Paraquat on Clarias gariepinus at a temperature range of $24.5-26.5^{\circ} \mathrm{C}$ which is similar to the conditions for the present study.

The findings from study indicated that the $P$. reticulata was able to detect the gradient of both pesticides, implying that the fishes have innate survival abilities provided there is opportunity to escape toxic conditions. At the highest concentrations of 15.0 and $4.0 \mathrm{mg} / \mathrm{L}$ for Paraquat and Dichlorvos respectively, $P$. reticulata recorded the highest levels of avoidance of $75 \%$ each demonstrating their high capacity for survival as three-quarters of their population were able to move away from toxic conditions. Despite these favorable levels of avoidance, $25 \%$ of the guppy populations remains exposed to the extent that should conditions change and they are unable to move away as in FS, then they make likely die. The consolation lies with the fact that the peak concentrations in the NFS exposures are less toxic than the $\mathrm{LC}_{50}$ values of both pesticides, thus enhancing their chances of survival in typical field conditions. Similarly, high levels of avoidance have been reported in the estuarine Whiteleg shrimp Litopenaeus vannamei $(80 \%)$ and the marine fish Rachycentron canadum (60\%) upon exposure to contaminant gradients of copper for 3-h (Araújo et al., 2016a). Regarding contaminants of emerging concern, studies of avoidance using NFS have been mainly performed with fishes. For instance, around $50 \%$ of a population of zebrafish (Danio rerio) avoided $1.4 \mathrm{mg} / \mathrm{L}$ of the fungicide (Pyrimethanil) (Araújo et al., 2014d, 2014b). Only 22\% of $P$. reticulata exposed under the same system for $4 \mathrm{~h}$ avoided triclosan concentrations as low as $0.2 \mathrm{mg} / \mathrm{L}$ (Silva et al., 2017). Morse so, the $\mathrm{AC}_{50}$ for $P$. reticulata exposed to a bisphenol gradient was reported to be as low as $0.15 \mathrm{mg} / \mathrm{L}$ (Silva et al., 2018). This implies that based on the chemistry of various pollutants, different responses are expected for the same species, thus indicating that pollution management for the sake of protecting a species must be toxicant specific. This also calls for studies involving exposure to combinations at environmentally relevant concentrations to effectively model avoidance responses.

Organisms' behavioral response to the presence of a contaminant by avoiding contaminated sites is a protective strategy to minimize toxic impact (Oliveira et al., 2013; Silva et al., 2017). The use of a nonforced exposure approach gives a simple demonstration of the immediate response of organisms due to the presence of contaminants and the potential for loss of species diversity due to large scale migration towards less aversive habitats (Rosa et al., 2012; Araújo et al., 2016b). Avoidance responses, despite its immediate value for organismal survival, might result disruptions in ecosystems which receive migrants as well (Moreira-Santos et al., 2019). Apparently, avoidance would be easier and practical when pollutants arise from point sources and/or from unidirectional sources, moving along water current than in cases of diffused sources or in large water bodies such as seas where turbulence is high. While 
migration from contaminated area is a solution for the avoiders (Moe et al., 2013), the consequences to ecosystem could prompt the loss of abundance and biodiversity (Lopes et al., 2004). For instance, avoidance by the shrimps, that involve an intermediate trophic level (Walker and Ferreira, 1985), might constrain the measure of food accessible to organisms in the upper trophic strata and decrease the predation pressure on lower trophic levels.

Investigation of population immediate decline in the two pesticide contamination scenarios (i.e., Paraquat and Dichlorvos exposures) demonstrated that avoidance assumed an increasingly more important role in population decline, for all concentrations, and was the determining factor in the Population Immediate Decline (PID). At higher concentrations of both test chemicals, the effects on the fish behavior and swimming patterns was chaotic. Oliveira et al. (2009) observed that the swimming pattern of $D$. rerio got modified at triclosan concentrations of 400 and $500 \mathrm{mg} / \mathrm{L}$. Such chaos might impair avoidance response as fishes might lose orientation which could have been of value for their avoidance movement. The typical patterns of avoidance and mortality reported in literature proposes that an underlying evasion reaction decides the population decrease in the very short-term, while at higher concentrations the ability to avoid contamination becomes impaired (Araújo et al., 2014b). Failures in the ability to identify contamination and consequent loss (due to unconsciousness) of the ability to avoid toxic concentrations have been observed in Cladocerans and Copepods (Gutierrez et al., 2012), amphibians (Araújo et al., 2014b), and fishes (Hartwell et al., 1989). In other studies, where PID was assessed, avoidance also tend to occur at concentrations lower than mortality (Rosa et al., 2012; Silva et al., 2017), demonstrating that under conditions of gradual and heterogeneous contamination, the contaminated area might lose part of the organism population due to its escaping from contamination with conceivable longer-term results on local ecosystem structure and functioning. In cases where the contaminant was observed to cause unconsciousness in the organisms (Gutierrez et al., 2012) and avoidance is prevented, the mortality in the short term might play a more significant role for the PID (Araújo et al., 2014a, c).

Regarding the non-forced exposure data, the PID caused by exposure to both test chemicals in this study was exclusively determined by the avoidance response rather than mortality. In any case, when the PID values were determined based on mortality results from the forced exposure, the outcomes were overestimated, since the concentrations which caused mortality in the FS were higher than in the NFS. The capacity to identify a pollution gradient and escape to more favorable habitat reduces the probability of suffering lethal effects. Notwithstanding, mortality data from FS is valuable for understanding the toxicity potential of a given concentration, and is more realistic for scenarios where a contamination gradient is not expected such as in ponds, lakes and slow flowing waters. Furthermore, there is a high level of uncertainty in mortality data derived from a NFS, since dead organisms found in a given concentration cannot be unequivocally linked to that concentration, because they could have migrated from another concentration. Thus, caution should be exercised in the use of mortality data from a NFS scenario for calculation of the PID. Such mortality data from NFS may be employed to provide an overview of contamination effects at the ecosystem or landscape level, instead of at the individual level or at the local spatial scale.

Page 12/19 


\subsection{Conclusion}

The outcomes of this study revealed the acute sensitivity of $P$. reticulata to both pesticides triggering its avoidance towards less polluted compartments. The responses observed indicated a decline in the population of $P$. reticulata exposed to various concentrations of both pesticides which was primarily driven by avoidance behaviour. The use of Forced System (FS) may be misleading in evaluating realistic environmental risks of the pesticides because spatial avoidance is not considered a possible response. Lethal effects can be overestimated in FS, due to mandatory exposure/confinement of naturally mobile organisms. Thus, it is advised that both types of exposure systems should be simultaneously integrated in ecological risk assessments for the most realistic recommendations.

\subsection{Declarations}

\section{ACKNOWLEDGEMENT}

The authors gratefully acknowledge Prof. E. O. Lawson (Department of Fisheries, Faculty of Science, Lagos state University) for his critical evaluations and corrections of the dissertation from which this manuscript was culled.

\subsection{References}

1. Araújo CV, Cedeño-Macías LA, Vera-Vera VC, Salvatierra D, Rodríguez EN, Zambrano U, Kuri S (2016a) Predicting the effects of copper on local population decline of 2 marine organisms, cobia fish and Whiteleg shrimp, based on avoidance response. Environmental toxicology chemistry 35(2):405-410

2. Araújo CV, Moreira-Santos M, Ribeiro R (2016b) Active and passive spatial avoidance by aquatic organisms from environmental stressors: a complementary perspective and a critical review. Environment international 92:405-415

3. Araújo CV, Shinn C, Mendes LB, Delello-Schneider D, Sanchez AL, Espíndola EL (2014b) Avoidance response of Danio rerio to a fungicide in a linear contamination gradient. Sci Total Environ 484:3642

4. Araújo CV, Shinn C, Moreira-Santos M, Lopes I, Espíndola EL, Ribeiro R (2014a) Copper-driven avoidance and mortality in temperate and tropical tadpoles. Aquatic toxicology 146:70-75

5. Araújo CV, Shinn C, Vasconcelos AM, Ribeiro R, Espíndola EL (2014c) Preference and avoidance responses by tadpoles: the fungicide pyrimethanil as a habitat disturber. Ecotoxicology 23(5):851860

6. Araújo CV, Shinn C, Vasconcelos AM, Ribeiro R, Espíndola EL (2014d) Preference and avoidance responses by tadpoles: the fungicide pyrimethanil as a habitat disturber. Ecotoxicology 23(5):851860

7. Araújo CVM, Shinn C, Moreira-Santos M, Ribeiro R (2017) What risks do the contaminants really represent? A standpoint on effects from organisms to ecosystems/landscapes based on non-forced 
aquatic exposure scenarios. In: Araújo CVM, Shinn C (eds) Ecotoxicology in Latin America. Nova Science Publishers, USA, pp 1-11

8. Arivu I, Muniyan M, Muthulingam M, Parthiban P, Ambedkar G, Kamalkanth S (2015) Toxicity of 2, 4Dichlorophenoxyacetic acid on freshwater fingerlings Labeo Rohita (Hamilton). World Journal of Pharmacy Pharmaceutical Sciences 4:1173-1190

9. Ayoola SO (2008) Histopathological effects of glyphosate on juvenile African catfish (Clarias gariepinus). Am Eurasian Journal of Agriculture Environmental Sciences 4(3):362-367

10. Banaee M, Davoodi MH, Zoheiri F (2013) Histopathological changes induced by paraquat on some tissues of gourami fish (Trichogaster trichopterus). Open Veterinary Journal 3(1):36-42

11. Damalas CA, Eleftherohorinos IG (2011) Pesticide exposure, safety issues, and risk assessment indicators. Int J Environ Res Public Health 8(5):1402-1419

12. Faust SD, Suffet IH (1966) Recovery, separation, and identification of organic pesticides from natural and potable waters. In Residue Reviews/Rückstands-Berichte pp. 44-116

13. Finney DJ (1971) Probit analysis: a statistical treatment of the sigmoid response curve. Cambridge university press, cambridge

14. Fryer JD (1977) Weed control Handbook edited by Make Peace GESAMP, 1: 384-389

15. Gilden RC, Huffling K, Sattler B (2010) Pesticides and health risks. Journal of Obstetric, Gynecologic \& Neonatal Nursing, 39(1): 103-110. Araújo, C. V., Moreira-Santos, M. and Ribeiro, R. (2016b). Active and passive spatial avoidance by aquatic organisms from environmental stressors: a complementary perspective and a critical review. Environment international, 92: 405-415

16. Günde EG, Yerli SV (2012) The comparative study on the acute toxicity of dichlorvos on guppy (Poecilia reticulata P., 1859) and carp (Cyprinus carpio L., 1758). Journal of Biology Chemistry 40(2):165-170

17. Gutierrez MF, Paggi JC, Gagneten AM (2012) Microcrustaceans escape behavior as an early bioindicator of copper, chromium and endosulfan toxicity. Ecotoxicology 21(2):428-438

18. Hartwell SI, Jin JH, Cherry DS, Cairns Jr J (1989) Toxicity versus avoidance response of golden shiner, Notemigonus crysoleucas, to five metals. J Fish Biol 35(3):447-456

19. Howard PH (1991) Handbook of environmental fate and exposure data for organic chemicals vol III. Lewis Publishers, Chelsea, pp 251-258

20. Kamwing L, Furtado JL (1977) Hydro-biologia 56, 49 (Chem. Abstr.) 8846293 (1978). In: The Bipyridium Herbicides (summers, 1980) Academic Press Incorporation (London) Ltd

21. Lamoreaux RJ, Newland LW (1978) The fate of dichlorvos in soil. Chemosphere 7(10):807-814

22. Lopes I, Baird DJ, Ribeiro R (2004) Avoidance of copper contamination by field populations of Daphnia longispina. Environmental Toxicology Chemistry: An International Journal 23(7):1702-1708

23. Moe SJ, De Schamphelaere K, Clements WH, Sorensen MT, Van den Brink PJ, Liess M (2013) Combined and interactive effects of global climate change and toxicants on populations and communities. Environmental toxicology chemistry 32(1):49-61 
24. Moreira-Santos M, Donato C, Lopes I, Ribeiro R (2008) Avoidance tests with small fish: Determination of the median avoidance concentration and of the lowest-observed-effect gradient. Environmental Toxicology Chemistry: An International Journal 27(7):1576-1582

25. Moreira-Santos RD, Paganin VA, Ticianelli EA (2019) Effects of temperature on the performance and $\mathrm{CO}$ tolerance of PEMFC with Aquivion ${ }^{\circledR}$ membrane. In Book of abstracts

26. OECD (2000) OECD guideline for testing of chemicals - fish. Juvenile Growth Test 301:231-236

27. Okoroiwu HU, Iwara IA (2018) Dichlorvos toxicity: A public health perspective. Interdisciplinary Toxicology 11(2):129-137

28. Oliveira C, Almeida JR, Guilhermino L, Soares AM, Gravato C (2013) Swimming velocity, avoidance behavior and biomarkers in Palaemon serratus exposed to fenitrothion. Chemosphere 90(3):936944

29. Oliveira R, Domingues I, Grisolia CK, Soares AM (2009) Effects of triclosan on zebrafish early-life stages and adults. Environ Sci Pollut Res 16(6):679-688

30. Oloruntuyi OO, Mulero O, Odukale B (1992) The Effects of Round off and Gramoxone on $C$. gariepinus Presented at the 10th Annual Conference of the Fisheries Society of Nigeria (FISON). Pp. 173-177, Abeokuta, Nigeria, 16-20 Nov. 1992

31. Omoniyi IT, Adeogun KL, Obasa SO (2013) Lethal effects of 2, 2-dichlorovinyl dimethyl phosphate (DDVP) on fingerling and juvenile Clarias gariepinus (Burchell, 1822). Croatian Journal of Fisheries 71(1):19-24

32. Owoeye O, Edem FV, Akinyoola BS, Rahaman S, Akang EE, Arinola GO (2012) Histological changes in liver and lungs of rats exposed to dichlorvos before and after vitamin supplementation. European Journal of Anatomy 16(3):190-198

33. Patar AA, Hassan WRM, Yusof FZM (2015) Acute toxicity of malathion, dichlorvos and temephos in climbing Perch (Anabas testudineus). Malaysian Applied Biology 44(3):37-42

34. Rahman MZ, Hossain Z, Mollah MFA, Ahmed GU (2002) Effect of Diazinon 60 EC on Anabas testudineus, Channa punctatus and Barbodes gonionotus. Naga the ICLARM quarterly 25(2):8-12

35. Rosa R, Materatski P, Moreira-Santos M, Sousa JP, Ribeiro R (2012) A scaled-up system to evaluate zooplankton spatial avoidance and the population immediate decline concentration. Environmental toxicology chemistry 31(6):1301-1305

36. Sarwar M (2015) The dangers of pesticides associated with public health and preventing of the risks. International Journal of Bioinformatics Biomedical Engineering 1(2):130-136

37. Silva DC, Araújo CV, França FM, Neto MB, Paiva TC, Silva FT, Pompêo ML (2018) Bisphenol risk in fish exposed to a contamination gradient: Triggering of spatial avoidance. Aquat Toxicol 197:1-6

38. Silva DC, Araújo CV, López-Doval JC, Neto MB, Silva FT, Paiva TC, Pompêo ML (2017) Potential effects of triclosan on spatial displacement and local population decline of the fish Poecilia reticulata using a non-forced system. Chemosphere 184:329-336 
39. USEPA (2007) Dichlorvos TEACH Chemical Summary U.S. EPA, Toxicity and Exposure Assessment for Children's http://www.epa.gov/teach/ Pp.1-13

40. USEPA: Unites States Environmental Protection Agency (1994) Integrated Risk Information System (IRS) on Dichlorvos. Environmental criteria and assessment office, office of Health and Environmental Assessment, Office of Research and Development Cincinnati, $\mathrm{OH}$

41. Varó I, Amat F, Navarro JC (2008) Acute toxicity of dichlorvos to Aphanius iberus (Cuvier \& Valenciennes, 1846) and its anti-cholinesterase effects on this species. Aquatic toxicology 88(1):5361

42. Varó I, Navarro JC, Amat F, Guilhermino L (2003) Effect of dichlorvos on cholinesterase activity of the European sea bass (Dicentrarchus labrax). Pestic Biochem Physiol 75(3):61-72

43. Verma SR, Rani S, Dalela RC (1982) Indicators of stress induced by pesticides in Mystus vittatus: Haematological parameters. Industrial journal of Environmental Health 24(1):58-64

44. Walker I, Ferreira MDN (1985) On the population dynamics and ecology of the shrimp species (Crustacea, Decapoda, Natantia) in the Central Amazonian river Tarumã-Mirim. Oecologia 66(2):264-270

45. WHO (1989) Dichlorvos, Environmental health criteria no. 79, International programme on chemical safety, Geneva

\section{Figures}

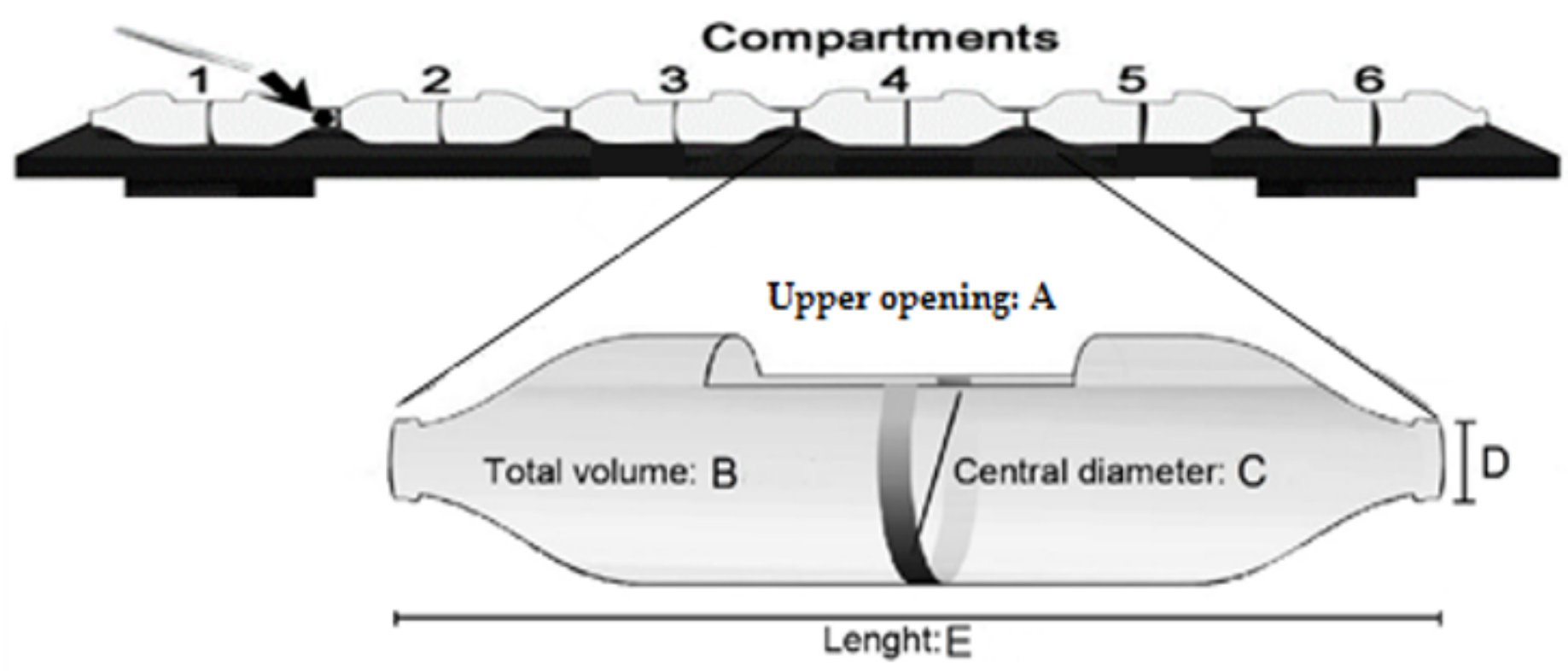

\section{Figure 1}


Schematic diagram of the static Non-Forced multi-compartmented System (NFS) utilized in the avoidance tests $(A=18 \times 6 \mathrm{~cm} ; B=1500 \mathrm{~mL} ; C=9 \mathrm{~cm} ; D=2 \mathrm{~cm} ; E=31 \mathrm{~cm})$. Source: Araújo et al., 2014a.

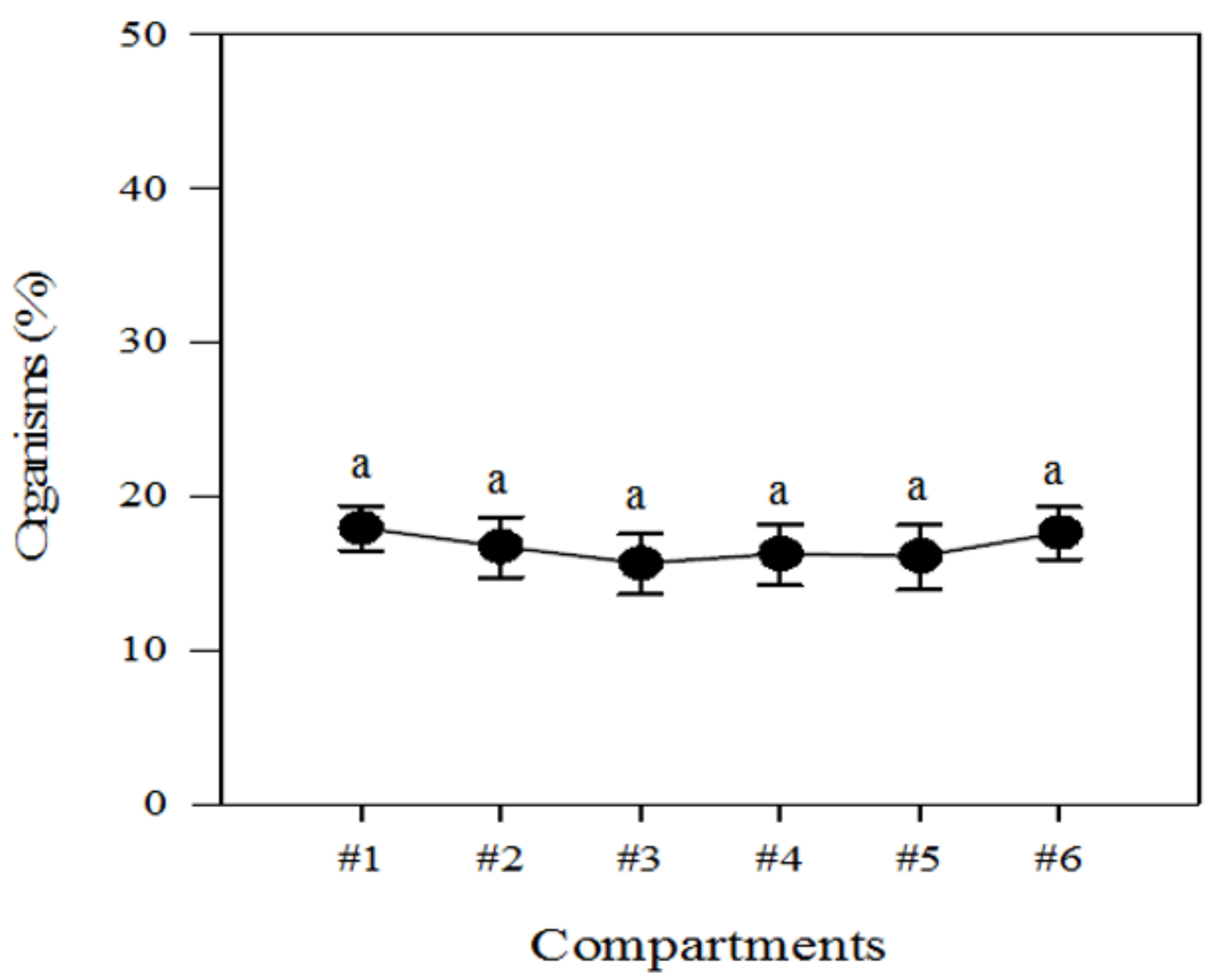

Figure 2

Mean percentage and standard deviation ( $\mathrm{n}=9$ observation periods) of the distribution of guppy fish (Poecilia reticulata) in the culture medium during control tests recorded in each compartment for 3-h. The letters represent statistically significant difference. 

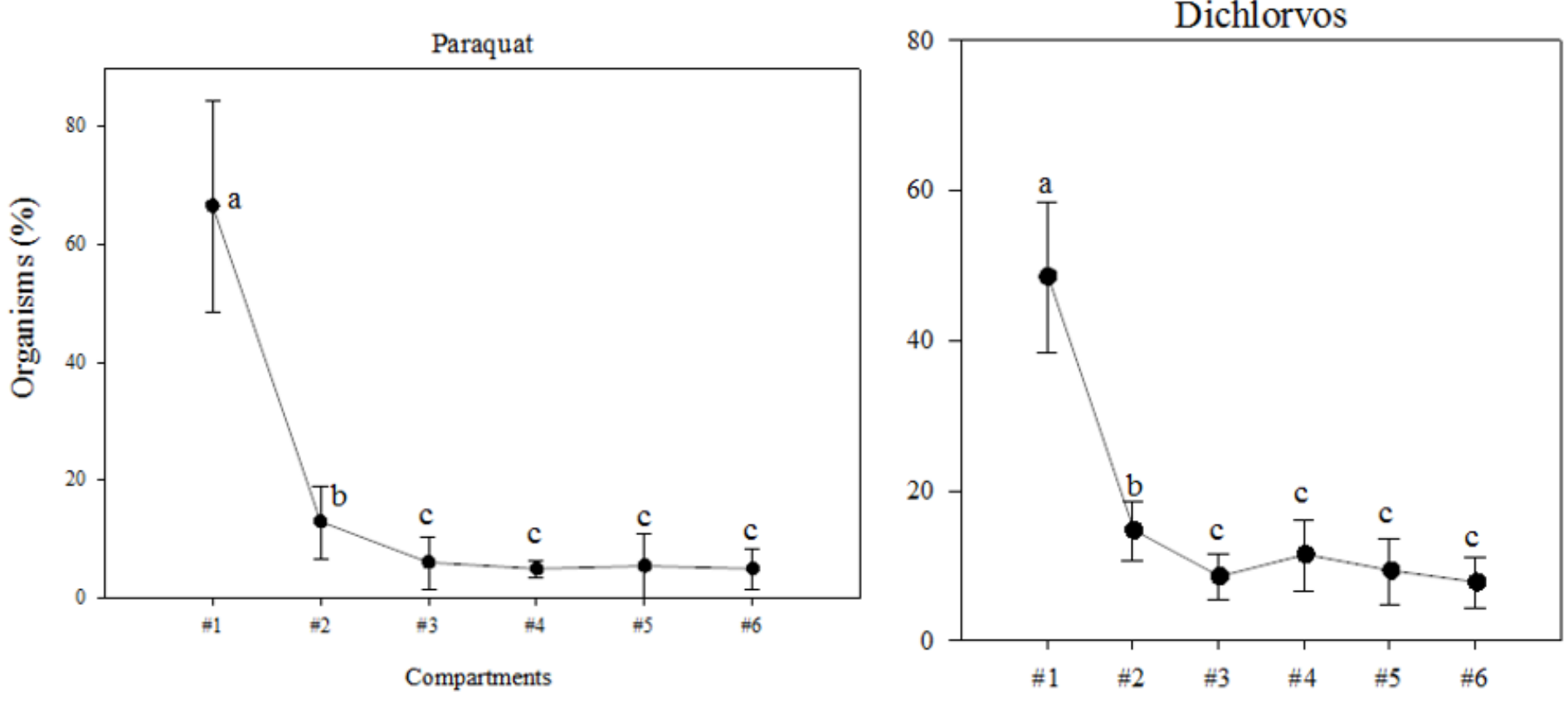

Compartments

Figure 3

Mean percentage and standard deviation ( $\mathrm{n}=9$ observation periods) of guppy fish (Poecilia reticulata) exposed to contamination gradients of Paraquat and Dichlorvos pesticides recorded in each compartment for $3 \mathrm{hr}$. Different letters represent statistically significant difference.
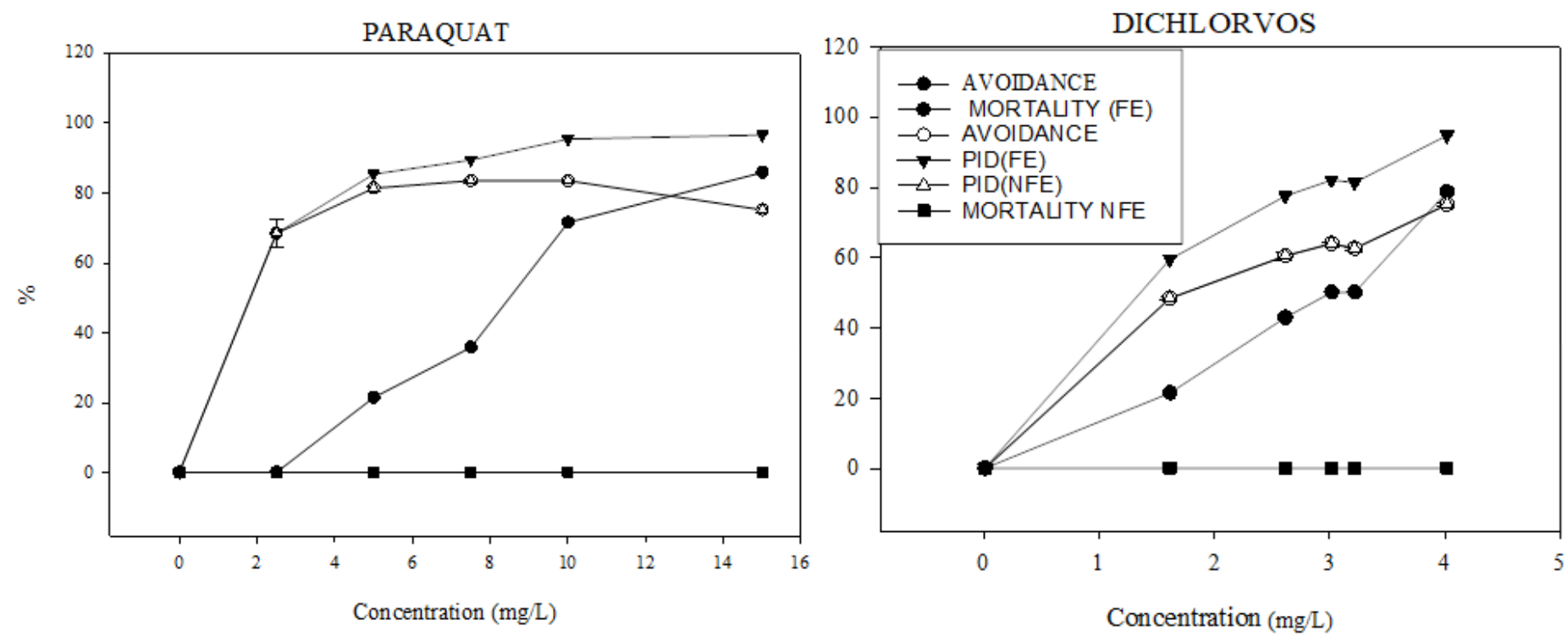

Figure 4

Concentration-response curves for the avoidance (Non-Forced System) and mortality (Forced System) responses, and the calculated PID (Population Immediate Decline) for Poecilia reticulata exposed to Paraquat herbicide and Dichlorvos insecticide. 


\section{Supplementary Files}

This is a list of supplementary files associated with this preprint. Click to download.

- SUPPLEMENTARYMATERIALS.docx 